\title{
Combined Open and Endoscopic Endonasal Skull Base Resection of a Rare Endometrial Carcinoma Metastasis
}

\author{
Melissa M. Stamates ${ }^{1}$ John M. Lee ${ }^{2}$ Ryan T. Merrell ${ }^{3}$ Michael J. Shinners ${ }^{4}$ Ricky H. Wong ${ }^{5}$
}

${ }^{1}$ Section of Neurosurgery, University of Chicago, Chicago, Illinois, United States

2 Department of Pathology and Laboratory Medicine, NorthShore University Health System, Evanston, Illinois, United States

${ }^{3}$ Department of Neurology, NorthShore University Health System, Evanston, Illinois, United States

${ }^{4}$ Department of Otolaryngology, NorthShore University Health System, Evanston, Illinois, United States

${ }^{5}$ Department of Neurosurgery, NorthShore University Health System, Evanston, Illinois, United States

Address for correspondence Ricky H. Wong, MD, MBA, Department of Neurosurgery, NorthShore University HealthSystem, 3rd Floor Kellogg Building, 2650 Ridge Avenue, Evanston, IL 60201, United States (e-mail: Wong.Ricky@gmail.com).

J Neurol Surg Rep 2018;79:e9-e13.

\begin{abstract}
In the absence of significant extracranial disease, patients with solitary brain metastases have shown benefit with resection. Brain lesions due to endometrial cancer are uncommon, and the only described skull base involvement is limited to the pituitary gland. We report the case of a 60-year-old female with endometrial cancer who presented with weeks of right cheek pain and numbness that was accompanied by

Keywords

- skull base metastasis

- endometrial carcinoma

- endoscopic endonasal approach

- neuro-oncology

- anatomic pathology

- middle fossa lesion headaches. We describe the magnetic resonance imaging (MRI) findings and surgical resection of a solitary endometrial metastasis involving the infratemporal fossa, middle fossa, cavernous sinus, trigeminal nerve, and nasal sinuses. Due to extensive nasal and lateral involvement, a combined open and endoscopic approach was planned. The patient was discharged home without complication. She underwent adjuvant radiotherapy. Despite its suspected indolent course, intracranial endometrial adenocarcinoma metastases are gaining higher prevalence. This case report documents the first direct neural spread of an endometrial primary, and highlights the potential for extraaxial sites of metastasis.
\end{abstract}

\section{Introduction}

Endometrial cancer can rarely present with brain metastasis at initial diagnosis or at recurrence. ${ }^{1}$ The vast majority reported are supratentorial lesions. ${ }^{2-6}$ Tumors that are treated with surgery and radiotherapy show a significant survival benefit than those treated with surgery or radiotherapy alone. ${ }^{1,7-11}$ Chemotherapy has not shown to significantly impact intracranial disease. $^{1}$

received

October 2, 2017

accepted

January 12, 2018
DOI https://doi.org/

10.1055/s-0038-1635098. ISSN 2193-6358.
In the absence of significant extracranial disease, patients with solitary brain metastases have shown benefit with resection. ${ }^{12-14}$ Brain lesions due to endometrial cancer are uncommon, and the only described skull base involvement is limited to the pituitary gland. ${ }^{15}$ An extensive skull base endometrial carcinoma metastasis has not been described, and therefore, optimal treatment remains unknown. We describe the magnetic resonance imaging (MRI) findings and surgical resection of a solitary endometrial metastasis
License terms

Stuttgart · New York

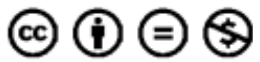




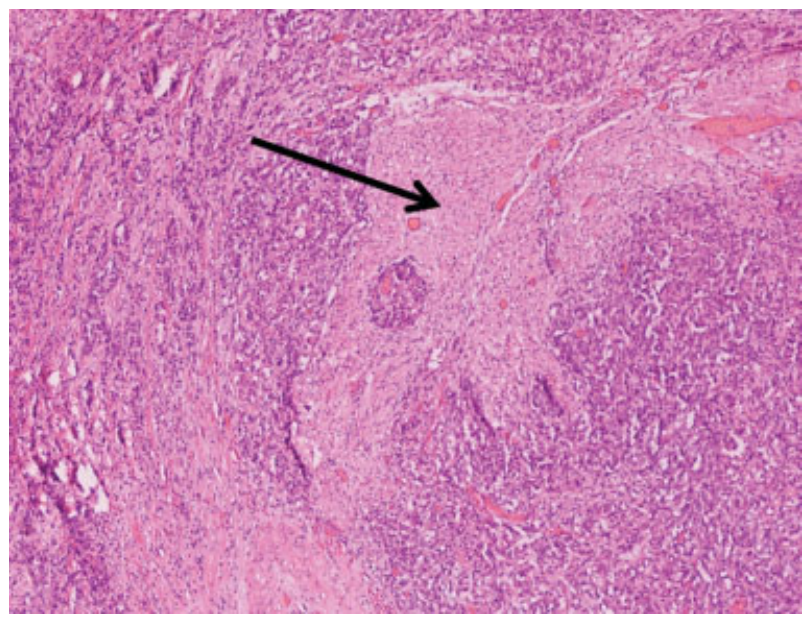

Fig. 1 Histologic specimen of trigeminal nerve stained with hematoxylin and eosin at $10 \times$ magnification. Arrow delineates normal cranial nerve, with inner foci of tumor. The immunostains on the specimen showed that it was positive for OSCAR, pankeratin, CD8/18, $E R$ (estrogen receptors), and PR (progesterone receptors). The immunochemical and focal histological findings were similar to that seen in the previous uterine specimen.

involving the infratemporal fossa, middle fossa, cavernous sinus, trigeminal nerve, and nasal sinuses.

\section{Case Report}

\section{History and Presentation}

We report the case of a 60-year-old female with International Federation of Gynecology and Obstetrics (FIGO) Stage IIIc2 endometrial cancer who presented with weeks of right cheek pain and numbness that was accompanied by headaches. Imaging revealed a large right-sided middle fossa and infratemporal mass that involved the cavernous sinus, nasal sinuses, and tracked along the trigeminal nerve into the posterior fossae. At the time of presentation, the patient had no sign of recurrence on abdominal imaging and had excellent functional status, Eastern Cooperative Oncology Group (ECOG) 1. Her previous treatment had included a total abdominal hysterectomy, bilateral salpingo-oophorectomy, pelvic lymphadenectomy, and omentectomy, along with pelvic radiation, vaginal cuff brachytherapy, and completion of six cycles of a carboplatin/ taxol regimen 18 months prior to her presentation at our clinic.

\section{Operation}

Due to extensive nasal (turbinates, sphenoid, and maxillary sinuses) and lateral (temporalis muscle) enhancement, a combined approach was planned, with open and endoscopic stages. A right orbitozygomatic approach was performed for cavernous sinus dural elevation and anterior petrosectomy with exposure of the petrous carotid artery. This allowed for resection of the middle fossa floor, temporal dura, and access to the infratemporal fossa tumor. The anterior petrosectomy allowed complete exposure of the trigeminal nerve, from Meckel's cave to its origin at the pons. The nerve was transected at the pons (-Fig. 1) and tumor removal proceeded anteriorly to the posterior maxillary sinus. The next day, the patient underwent an extended endonasal approach to the infratemporal fossa. The right nasal turbinates were removed in their entirety, followed by removal of tumor in the sphenoid sinus and clival recess. The resection then proceeded laterally through the pterygoid wedge and plates and temporalis muscles. Residual tumor was left in the cavernous sinus, along the parapharyngeal carotid and internal jugular vein, and along the lateral soft palate to prevent an oral-antral fistula.

\section{Postoperative Course}

The patient was discharged to home on postoperative day 3. She returned to clinic for routine wound check at 2 weeks and began intensity-modulated radiation therapy (IMRT) 1 month after surgery. Systemic chemotherapy (Tamoxifen and Megace) followed radiation. Postoperative films confirmed significant tumor debulking (-Figs. 2 and 3), with evidence of intended residual at the right cavernous sinus. The patient is alive and well at 12 months following surgery.

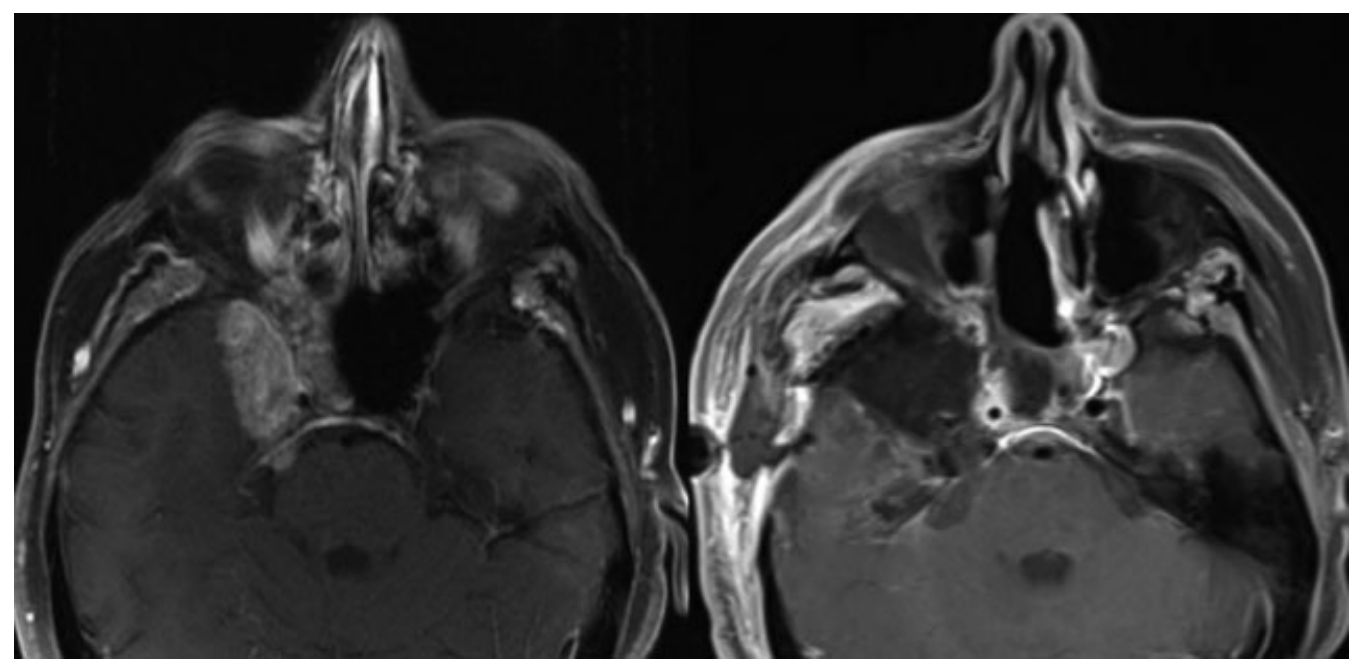

Fig. 2 Axial magnetic resonance imaging at level of right trigeminal root on presentation (left) and after resection (right). 


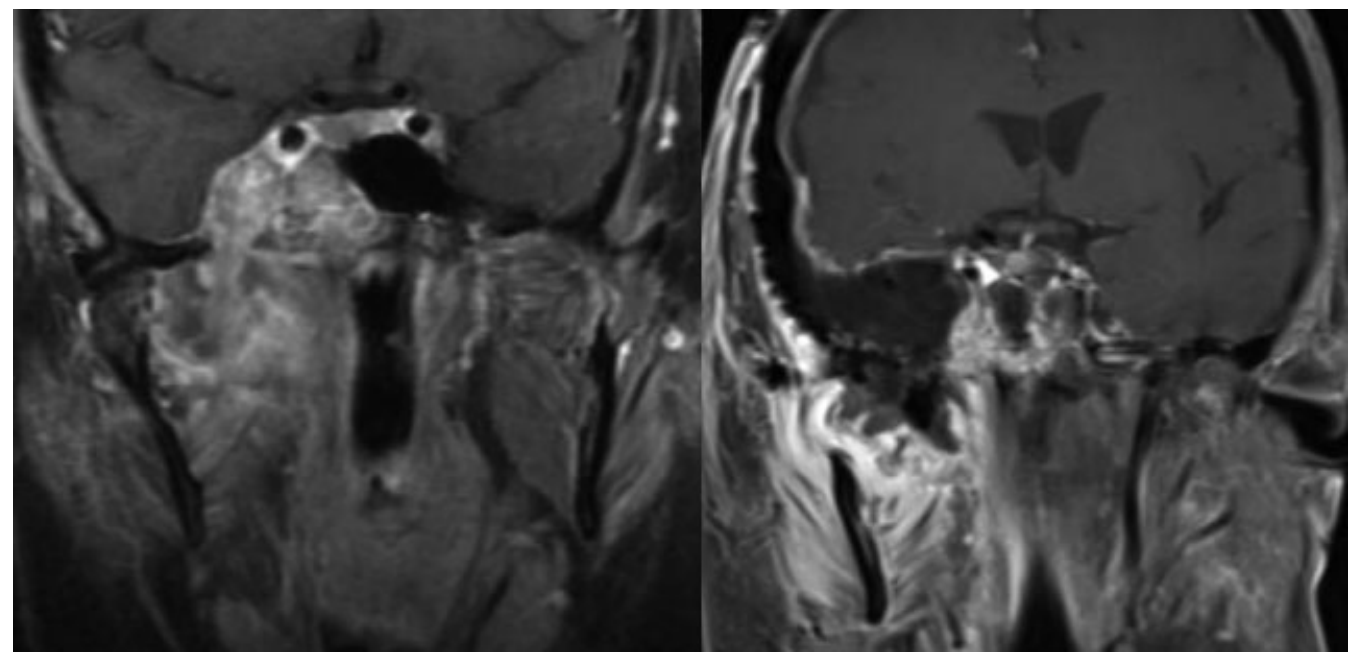

Fig. 3 Coronal magnetic resonance imaging at root of zygoma on presentation (left) and after resection (right).

\section{Discussion}

Intracranial disease is a rare $(<1 \%)$ complication of endometrial cancer, the most common gynecologic cancer. ${ }^{16-19}$ The most common sites of endometrial metastases include pelvic lymph nodes, vagina, peritoneum, or lung. ${ }^{20}$ There were 53 reports of intracranial metastases in 2007, reviewed by Orrrú et al; ${ }^{3}$ cases reported after this date are summarized in -Table $\mathbf{1}$. Risk factors for intracranial metastasis include poorly differentiated histology, higher FIGO grade, and myometrial or lymphovascular invasion. ${ }^{21,22}$ Our patient exhibited all of these traits.

With respect to treatment of intracranial endometrial disease, experience is limited to infrequent case reports, with few studies discussing more than two patients. $3,4,6,7,9,11,17,21$ With these prior studies reporting survival benefit of combined therapy with surgical resection and radiation, versus surgery or radiation alone, a combined approach was planned for our skull base lesion with invasion of the trigeminal nerve.

Table 1 Endometrial intracranial disease reported in the literature after 2007

\begin{tabular}{|c|c|c|c|c|c|c|c|}
\hline Authors and year & $\begin{array}{l}\text { No. of } \\
\text { cases }\end{array}$ & $\begin{array}{l}\text { Median age at } \\
\text { diagnosis of } \\
\text { IC disease (y) }\end{array}$ & $\begin{array}{l}\text { Location } \\
\text { of brain } \\
\text { lesions }\end{array}$ & $\begin{array}{l}\text { Multiple } \\
\text { brain } \\
\text { metastases }\end{array}$ & $\begin{array}{l}\text { EC } \\
\text { disease } \\
\text { present }\end{array}$ & Treatment & $\begin{array}{l}\text { Median survival } \\
\text { after diagnosis } \\
\text { of IC (mo) }\end{array}$ \\
\hline Al-Mujaini et al, $2008^{23}$ & 1 & 69 & ST & Yes & Yes & NS & NS \\
\hline Monaco et al, $2008^{21}$ & 6 & 60 & ** & NS & NS & RT (6) & 7 \\
\hline Ramirez et al, $2008^{24}$ & 1 & 61 & ST & Yes & No & RT & 17 \\
\hline Asensio et al, $2009^{25}$ & 1 & 72 & LM & No & No & $\mathrm{RT}+\mathrm{CHT}$ & 4 \\
\hline Srikantia et al, $2009^{26}$ & 1 & 41 & ST & Yes & Yes & RT & NS \\
\hline Forster et al, $2011^{27}$ & 1 & 58 & ST & Yes & Yes & $\mathrm{RT}+\mathrm{CHT}$ & 10 \\
\hline Cabuk-Comert et al, $2012^{28}$ & 2 & NS & IT (2) & $\begin{array}{l}\text { Yes }=1 \\
\text { No }=1\end{array}$ & Yes $=2$ & RT (1) & 17.5 \\
\hline Gulsen and Terzi, $2013^{29}$ & 1 & 71 & $\mathrm{ST}+\mathrm{IT}$ & Yes & No & Surgery + RT + CHT & 9 \\
\hline Nassir et al, $2014^{8}$ & 1 & 74 & ST & Yes & No & Surgery + RT & 13 \\
\hline Gressel et al, $2015^{9}$ & 22 & 56 & ** & $\begin{array}{l}\text { Yes }=14 \\
\text { No }=8\end{array}$ & $\begin{array}{l}\text { Yes }=17 \\
\text { No }=5\end{array}$ & $\begin{array}{l}\text { Surgery (1), RT (15), } \\
\text { Surgery + RT (2), } \\
\text { Pall (4) }\end{array}$ & 4.5 \\
\hline Kim et al, $2015^{11}$ & 19 & 58 (mean) & NS & $\begin{array}{l}\text { Yes }=8 \\
\text { No }=11\end{array}$ & $\begin{array}{l}\text { Yes }=8 \\
\text { No }=11\end{array}$ & $\begin{array}{l}\text { Surgery + RT (9), } \\
\text { RT (5), Pall (2), } \\
\text { CHT (3) }\end{array}$ & 23 (mean) \\
\hline Sawada et al, $2016^{30}$ & 1 & 40 & IT & No & Yes & Surgery + RT & 144 \\
\hline Uccella et al, $2016^{31}$ & 18 & 64 & $\begin{array}{l}\text { ST (12), IT (2), } \\
\text { ST + IT (4) }\end{array}$ & $\begin{array}{l}\text { Yes }=9 \\
\text { No }=9\end{array}$ & $\begin{array}{l}\text { Yes }=11 \\
\text { No }=7\end{array}$ & $\begin{array}{l}\text { RT (6), RT + CHT (1), } \\
\text { Surgery + RT (8), } \\
\text { Pall (3) }\end{array}$ & 6.5 \\
\hline Kimyon et al, $2017^{1}$ & 1 & 69 & $* *$ & No & No & Surgery + RT & 21 \\
\hline Toyoshima et al, $2017^{32}$ & 2 & 62 & LM & No & NS & Pall & 1.5 \\
\hline
\end{tabular}

Abbreviations: CHT, chemotherapy; EC, extracranial; IC, intracranial; IT, infratentorial; LM, leptomeningeal; NS, not stated; Pall, palliative care; RT, radiotherapy; ST, supratentorial.

** Stated "brain metastases" or "cerebral mass" without further detail. 
The patient's constellation of symptoms has been designated the "middle fossa syndrome" by Greenberg et al when describing clinical characteristics of skull base lesions. ${ }^{33}$ The origin of this tumor is somewhat ambiguous due to its large size, but we suspect it centered at the pterygopalatine fossa. Although there are previous reports of intracranial endometrial metastases, this is the first reported skull base metastasis from an endometrial primary, treated with aggressive debulking via a combined open and extended endoscopic approach.

An extended endonasal approach complemented our craniotomy. The craniotomy gave us access to perform complex dural repair and insert a rigid cranioplasty to separate the middle fossa and intracranial space from the nasal cavity after an extensive bony resection. ${ }^{34}$ The endoscope provided access to tumor medial to the cavernous sinus in the sphenoid sinus, clival recess, as well as the turbinates in the nasal cavity. In preoperative discussion with the patient, planned residual was left in the cavernous sinus due to lack of significant cranial nerve palsies. Three month's MRI revealed continued decrease in residual tumor volume.

In regards to skull base metastases, endoscopy has expanded access along, most notably the anterior skull base, but also the middle and posterior fossae. The benefits of using the endoscopic approach for our patient included avoiding a transfacial or transoral procedure with associated morbidity of oral-antral fistula, need for a lateral rhinotomy incision along the face and higher infection rates associated with transoral approaches. The patient was able to have her diet and activity advanced immediately after surgery, and was able to discharge once pain was well-controlled on oral analgesics.

Despite its suspected indolent course and previous reference as a "neurophobic" tumor, ${ }^{8}$ intracranial endometrial adenocarcinoma metastases are gaining higher prevalence in the U.S. population due to better survival rates. Further study should focus on multicenter pooling of data to determine the best treatment of this disease and to characterize the site of metastases. In addition to this report, there are other documented endometrial adenocarcinoma cases involving the scalp, ${ }^{35,36}$ cranial bones, ${ }^{37}$ and paranasal sinuses, ${ }^{38,39}$ suggesting the incidence of distant endometrial metastases remains unknown. This case report documents the first direct neural spread of an endometrial primary, and highlights the potential for extra-axial sites of metastasis.

\section{Disclosures}

The authors report no conflict of interest concerning the materials or methods used or the findings specified in this paper.

\section{Conflicts of Interest/Financial Disclosures None.}

\section{Acknowledgments}

The authors wish to thank Vimal Patel, PhD, Medical and Scientific Writer at NorthShore Neurological Institute for copy editing this manuscript for submission.

\section{References}

1 Kimyon G, Turan T, Basaran D, et al. Is neurosurgery with adjuvant radiotherapy an effective treatment modality in isolated brain involvement from endometrial cancer?: from case report to analysis Int J Gynecol Cancer 2017;27(02):315-325

2 Ruelle A, Zuccarello M, Andrioli G. Brain metastasis from endometrial carcinoma. Report of two cases. Neurosurg Rev 1994;17 (01):83-87

3 Orrrù S, Lay G, Dessì M, Murtas R, Deidda MA, Amichetti M. Brain metastases from endometrial carcinoma: report of three cases and review of the literature. Tumori 2007;93(01):112-117

4 Gien LT, Kwon JS, D'Souza DP, et al. Brain metastases from endometrial carcinoma: a retrospective study. Gynecol Oncol 2004;93(02):524-528

5 Wroński M, Zakowski M, Arbit E, Hoskins WJ, Galicich JH. Endometrial cancer metastasis to brain: report of two cases and a review of the literature. Surg Neurol 1993;39(05):355-359

6 Cormio G, Lissoni A, Losa G, Zanetta G, Pellegrino A, Mangioni C. Brain metastases from endometrial carcinoma. Gynecol Oncol 1996;61(01):40-43

7 Mahmoud-Ahmed AS, Suh JH, Barnett GH, Webster KD, Belinson JL, Kennedy AW. The effect of radiation therapy on brain metastases from endometrial carcinoma: a retrospective study. Gynecol Oncol 2001;83(02):305-309

8 Nassir M, Roth A, Gasimli K, et al. Is endometrial cancer really a neurophobic tumor? A case report and review of the literature. Anticancer Res 2014;34(01):249-257

9 Gressel GM, Lundsberg LS, Altwerger G, et al. Factors predictive of improved survival in patients with brain metastases from gynecologic cancer: a single institution retrospective study of 47 cases and review of the literature. Int J Gynecol Cancer 2015;25(09):1711-1716

10 Dziggel L, Janssen S, Bajrovic A, et al. Local therapies can improve intracerebral control in patients with cerebral metastasis from gynecological cancers. Anticancer Res 2016;36(09):4777-4780

$11 \mathrm{Kim}$ YZ, Kwon JH, Lim S. A clinical analysis of brain metastasis in gynecologic cancer: a retrospective multi-institute analysis. J Korean Med Sci 2015;30(01):66-73

12 Bajaj GK, Kleinberg L, Terezakis S. Current concepts and controversies in the treatment of parenchymal brain metastases: improved outcomes with aggressive management. Cancer Invest 2005;23(04):363-376

13 Noordijk EM, Vecht CJ, Haaxma-Reiche $\mathrm{H}$, et al. The choice of treatment of single brain metastasis should be based on extracranial tumor activity and age. Int J Radiat Oncol Biol Phys 1994; 29(04):711-717

14 Patchell RA, Tibbs PA, Walsh JW, et al. A randomized trial of surgery in the treatment of single metastases to the brain. N Engl J Med 1990;322(08):494-500

15 Lieschke GJ, Tress B, Chambers D. Endometrial adenocarcinoma presenting as pituitary apoplexy. Aust N Z J Med 1990;20(01):81-84

16 Schiff D, Wen PY. Cancer Neurology in Clinical Practice. Totowa, NJ: Humana Press; 2003

17 Kottke-Marchant K, Estes ML, Nunez C. Early brain metastases in endometrial carcinoma. Gynecol Oncol 1991;41(01):67-73

18 Ogawa K, Yoshii Y, Aoki Y, et al. Treatment and prognosis of brain metastases from gynecological cancers. Neurol Med Chir (Tokyo) 2008;48(02):57-62, discussion 62-63

19 Piura E, Piura B. Brain metastases from endometrial carcinoma. ISRN Oncol 2012;2012:581749

20 Sohaib SA, Houghton SL, Meroni R, Rockall AG, Blake P, Reznek RH. Recurrent endometrial cancer: patterns of recurrent disease and assessment of prognosis. Clin Radiol 2007;62(01):28-34, discussion 35-36

21 Monaco E III, Kondziolka D, Mongia S, Niranjan A, Flickinger JC, Lunsford LD. Management of brain metastases from ovarian and endometrial carcinoma with stereotactic radiosurgery. Cancer 2008;113(09):2610-2614 
22 Gadducci A, Cavazzana A, Cosio S, et al. Lymph-vascular space involvement and outer one-third myometrial invasion are strong predictors of distant haematogeneous failures in patients with stage I-II endometrioid-type endometrial cancer. Anticancer Res 2009;29(05):1715-1720

23 Al-Mujaini A, Gans M, Deschênes J. Cortical visual loss consequent to brain metastases from an endometrial carcinoma. Can J Ophthalmol 2008;43(04):486

24 Ramirez C, Reyns N, Pasquier D, Blond S. Bilateral thalamic metastases in endometrial adenocarcinoma. Eur Neurol 2008;59(06):330

25 Asensio N, Luis A, Costa I, Oliveira J, Vaz F. Meningeal carcinomatosis and uterine carcinoma: three different clinical settings and review of the literature. Int J Gynecol Cancer 2009;19(01):168-172

26 Srikantia N, B R, A G R, Kalyan SN. Endometrioid endometrial adenocarcinoma in a premenopausal woman with multiple organ metastases. Indian J Med Paediatr Oncol 2009;30(02):80-83

27 Forster MD, Dedes KJ, Sandhu S, et al. Treatment with olaparib in a patient with PTEN-deficient endometrioid endometrial cancer. Nat Rev Clin Oncol 2011;8(05):302-306

28 Cabuk-Comert E, Bildaci TB, Kisa-Karakaya B, et al. Outcomes in 12 gynecologic cancer patients with brain metastasis: a single center's experience. Turk J Med Sci 2012;42:385-394

29 Gulsen S, Terzi A. Multiple brain metastases in a patient with uterine papillary serous adenocarcinoma: treatment options for this rarely seen metastatic brain tumor. Surg Neurol Int 2013;4:111

30 Sawada M, Inagaki M, Ozaki M, et al. Long-term survival after brain metastasis from endometrial cancer. Jpn J Clin Oncol 1990; 20(03):312-315
31 Uccella S, Morris JM, Multinu F, et al. Primary brain metastases of endometrial cancer: a report of 18 cases and review of the literature. Gynecol Oncol 2016;142(01):70-75

32 Toyoshima M, Tsuji K, Shigeta S, et al. Leptomeningeal metastasis from gynecologic cancers diagnosed by brain MRI. Clin Imaging 2017;41:42-47

33 Greenberg HS, Deck MD, Vikram B, Chu FC, Posner JB. Metastasis to the base of the skull: clinical findings in 43 patients. Neurology 1981;31(05):530-537

34 Wong RH, Agazzi S, van Loveren H. "Inverted Gull Wing" dural closure and middle fossa floor reconstruction after transzygomatic infratemporal fossa approach. World Neurosurg 2016; 89:280-284

35 Farooq MU, Chang HT. Intracranial and scalp metastasis of endometrial carcinoma. Med Sci Monit 2008;14(09):CS87-CS88

36 Kushner DM, Lurain JR, Fu TS, Fishman DA. Endometrial adenocarcinoma metastatic to the scalp: case report and literature review. Gynecol Oncol 1997;65(03):530-533

37 Walrath JD, Lelli GJ Jr, Engelbert M, Kazim M. Metastatic endometrial carcinoma resulting in orbital apex compression. Ophthal Plast Reconstr Surg 2007;23(03):250-251

38 Ilvan S, Akyildiz EU, Calay Z, Celikoyar M, Sahinler I. Endometrial clear cell carcinoma metastatic to the paranasal sinuses: a case report and review of the literature. Gynecol Oncol 2004;94(01): $232-234$

39 Scott A, Raine M, Stansbie JM. Ethmoid metastasis of endometrial carcinoma causing mucocoele of maxillary antrum. J Laryngol Otol 1998;112(03):283-285 